\title{
THE INTERDEPENDENCE BETWEEN THE FINANCIAL SECTOR AND BUSINESS SECTOR IN ASEAN 4 COUNTRIES
}

\author{
Aulia Keiko Hubbansyah \\ Faculty of Economics, Universitas Djuanda, Indonesia \\ (keikohubbansyah91@gmail.com) \\ Zaafri Ananto Husodo \\ Faculty of Economics and Business, Universitas Indonesia, Indonesia \\ (z.husodo@gmail.com)
}

\begin{abstract}
In this study, we analyze the dynamic interactions between the financial sectors and the business sectors in the ASEAN-4 countries (Indonesia, Malaysia, Thailand and Singapore). To do that, we apply the newly generalized version of the Vector Autoregressive Framework (VAR) spillover index approach proposed by Diebold and Yilmaz (2012) as our method of analysis. Based on quarterly data of each variable over the period from the first quarter of 1984 to the fourth quarter of 2015 for the ASEAN-4 countries, this study finds that: 1) Spillovers between the variables move in a diverse manner over the period of analysis for each country, 2) The variable that acts as the dominant crisis transmitter in each country is different for each country, 3) The interdependence between the variables became stronger, both within and across the countries, during the crisis period. In particular, the business sectors played a leading role during the onset of the crisis, while the financial sectors took their places as the dominant source of spillovers as the crisis deepened. 4) Credit growth in Thailand was found to be the dominant transmitter of shocks to the ASEAN-3 countries. Overall, these results suggest that the strength and movement of the spillovers between the financial and business sectors changed from time to time along with the changes that happened in the economies.
\end{abstract}

Keywords: financial sector, business sector, financial cycle, business cycle, spillover, crisis

JEL Classification: E32, H12, G15, F44 


\section{INTRODUCTION}

In the aftermath of the 2008-2009 crisis, many studies have been devoted to analyzing the effect of financial friction on business cycle and the interrelationship between the financial sector and real economic activity (Schularick \& Taylor, 2012; Dees, 2016). Related to these concerns, the prior studies have found that there is no country - or even sector in the economy - that can hide the cyclical trend in the financial sector (Baur, 2012; Aizenman, Pinto \& Sushko, 2013), the impact of the financial turbulence was found not only locally, but it may also spill into other country accelerated by their financial openness regimes (Antonakakis, Breitenlechner, \& Scharler, 2015; Aizenman et al., 2013). Furthermore, recessions which are accompanied by financial friction are generally deeper and last longer (Dees, 2016; Claessens \& Kose, 2013; Jordà, Schularick, \& Taylor, 2013).

Although the previous research findings have helped us to portray the link between the dynamics of the financial sector and the real sector activity, however, most of the earlier studies still limited themselves to static analyses. In response to this gap, the purpose of this paper is to analyze the time-varying relationship between the financial and real sectors at business cycle frequencies. Operationally, we try to develop the previous studies in some way. First, this paper uses a bidirectional analysis for analyzing and understanding the relationship between both sectors. It is because theoretical, as well as empirical contributions, show that the dynamics of the financial sector and business sector are basically interrelated with causality potentially coming from both directions.

Second, we modify the proxies. For the business cycle, we prefer to use the Index of Industrial Production (IIP) growth as a proxy for the business cycle instead of GDP growth. This is done because it is difficult to ensure the quality of the GDP's data at a quarterly frequency especially for developing countries, and the output of the industrial sector roughly corresponds to the output in traded goods and is closely related to the dynamics of the business sector (Rand \& Tarp, 2002). In developing countries, the value added by industrial production generally represents a substantial share of GDP. Based on these arguments, IIP growth is a reasonable proxy for measuring the business sector's cycle. For the financial cycle, we use the cycles of three different market sectors, which together establish the core of financial intermediation. Specifically, we focus on the cycles of the credit, property and equity markets. Although credit growth was empirically found to be a predictor and natural proxy of financial crises (Schularick \& Taylor, 2012; Claessens et al., 2011), property and equity prices, are also good indicators of subsequent episodes of financial instability. Empirically, financial crises are often started by asset price booms that eventually turn into busts. Based on these arguments, the combination of credit and variable assets will be good proxies of the financial cycles. Moreover, conceptually involving variable asset for analyzing the dynamics of the financial sector, as related to the real economy, is important, because it is still not clearly known from previous studies about the interplay between them in the time-varying context of generating the economy.

In order to meet the aim of this study, we adopt the VAR-based spillover index approach proposed by Diebold and Yilmaz (2012), which extends the methodology previously introduced in Diebold and Yilmaz (2009), as our method of analysis. One of the main advantages of using this approach is it allows us to decompose spillovers into those coming from (or to) a particular fundamental source, so that we can identify which variables act as the main 
recipients and transmitters of shocks (Antonakakis et al., 2015). The dynamic evolution of the importance of the financial cycle's and business cycle's spillover effect can be tracked using a rolling window estimation and illustrated using spillover plots. Moreover, another advantage of this method is its ability to overcome the difficulties encountered in defining the order of the variables when analyzing the spillover effect among the observed variables. It is because this method adapts the generalized VAR framework proposed by Koop, Pesaran, and Potter (1996), resulting in Forecast Error Variance Decompositions (FEVD) which are invariant to the ordering of the variables. In the context of the present study, this is important since it is difficult to set up one particular causal ordering of the variables. Theoretical, as well as empirical contributions, suggest that the dynamics in the financial sectors and business sectors are strongly intertwined with causality potentially running in both directions (Antonakakis et al. 2015).

In analyzing the interdependence between the financial and business sectors, we use ASEAN countries as our sample. This is because the economic relations between the countries in ASEAN are likely to increase in recent years, not only in terms of their real economic activity but also in their financial sectors (Azis, 2013; Almekinders, Fukuda, Mourmouras, \& Zhou 2015). It is projected that this trend will be more profound in the years to come along with the implementation of the ASEAN Economic Community (AEC). A consequence of this increasingly intense economic relationship is that an economic setback in one sector may affect the activity of the economic sectors both within and across the countries. Thus, there is a need to understand the interdependence between the financial and business sectors both within and across countries.

Operationally, we only involve four ASEAN countries namely Indonesia, Thailand, Malaysia and Singapore as our sample. At first, we wanted to accommodate all the ASEAN countries. However, we found difficulties concerning the data's availability. Only these four countries have all the required data for the entire period of our analysis. Even so, this condition does not undermine the context of the analysis because these countries (Indonesia, Thailand, Malaysia and Singapore) account for nearly 70 percent of the ASEAN economy. Therefore, these four countries are already representing the ASEAN economy (ASEAN Statistic, 2016).

This paper is presented as follows: Section 2 discusses the findings of the existing literature related to the focus that is being addressed in this study. Section 3 discusses the usage of the spillover index approach, turning point analysis and the empirical findings of this research. Section 4 summarizes the results and the conclusions of the study. Section 5 states the limitations and suggestions for further studies.

\section{LITERATURE REVIEW}

Basically, the relationship between the financial sector and real economic activity is one of the main issues studied in the economic literature. Earlier studies have stressed the important role played by the financial sector in supporting and driving growth in the real sector (Goldsmith, 1969; McKinnon, 1973; Shaw, 1973; King \& Levine, 1993). Interestingly, these findings refuted some of the views of numerous influential economists who believed that finance was a relatively unimportant factor in economic development (look at Robinson, 1952; Modigliani et al. 1958). 
However, these minimal views regarding the role of the financial sector in the economy have changed. This happened due to the emergence of various phenomena showing that the deteriorating condition of the financial sector was the source of the instability in the real sector (Bernanke, Gertler, \& Gilchrist, 1999). These facts foster awareness of the importance of the role of the financial sector for the business sector, so that, in the later studies, the focus of the discussion is no longer intended to analyze the role of the financial sector relative to the real sector, but to lead to a discussion of the characteristics of each sector, and how they interact.

Related to the above, Baur (2012) who studied the effect of the financial crisis on the business sector, finds that the crisis tends to increase the co-movement returns among financial sector stocks across countries and between financial sector stocks and real economy stocks. The results demonstrate that no country and sector were immune to the adverse effects of the crisis, limiting the effectiveness of portfolio diversification. However, there is clear evidence that some sectors, in particular healthcare, telecommunications and technology were less severely affected by the crisis.

Aizenman et al. (2013) tries to examine how financial cycles affect the broader economy through their impact on real economic sectors. He finds that periods of accelerated growth by the financial sector are more likely to be followed by abrupt financial contractions than are periods of slower financial sector growth. Sharp fluctuations in the financial sector have strongly asymmetric effects, with the majority of real sectors adversely affected by contractions, but not helped by expansions. The adverse effects of financial contractions are transmitted almost exclusively through the financial openness channels, with precautionary foreign exchange reserve holdings serving as a key buffer.

Antonakakis et al. (2015) who studied the interactions between the financial cycle's and the business cycle's spillovers in the G7 countries has found that spillovers between both sectors evolve heterogeneously over time and across countries; are bidirectional in nature; and there is an interchanging role between the financial sector and the business sector during the crisis period where the financial sector plays a dominant role during the early stages of the crisis, while the real sector quickly takes over as the dominant source of spillovers.

Although the findings of the aforementioned studies have been able to illustrate the relationship between the financial and business sectors, there is still room to develop the previously discussed studies. Unlike Baur (2012) and Aizenman et al. (2013), but relatively similar to Antonakakis et al. (2015), we use bidirectional perspectives for analyzing the relationship between the financial cycles and business cycles spillover. This perspective is supported both theoretically and empirically (Apostoaie \& Percic, 2014). But differing with Antonakakis et al. (2015), we modify and develop the proxies for the business cycle and financial cycle.

For the business cycle, we prefer to use the Index of Industrial Production (IIP) growth as a proxy for the business cycle, instead of GDP growth. Because it is difficult to ensure the quality of the GDP's data at a quarterly frequency, especially for developing countries, and the output of the industrial sector roughly corresponds to the output in traded goods, and is closely related to the dynamics of the business sector. In developing countries, the value added by industrial production generally represented a substantial share of GDP. Based on these 
arguments, IIP growth is a reasonable proxy for measuring the business sector's cycle.

For the financial cycle, we focus on the cycles of three different market segments, which together establish the core of financial intermediation. Specifically, we focus on cycles in the credit, property and equity markets. Although credit growth was empirically found to be a predictor and natural proxy of financial crises (Schularick \& Taylor, 2012; Claessens et al., 2011), property and equity prices are also good indicators of subsequent episodes of financial instability. Empirically, financial crises are often started by asset price booms that eventually turn into busts. Based on these arguments, the combination of the credit and asset variables will be good proxies for financial cycles.

Related to the above, Claessens et al., (2011) that tried to discuss the characteristics of financial cycles and reported three main results. First, financial cycles tend to be persistent and harsh, especially those in the housing and equity markets. Second, financial cycles are highly synchronized within countries, particularly credit and house price cycles. Third financial cycles accentuate each other and become magnified, especially during coincident downturns in the credit and housing markets. Claessens et al.'s (2011) findings have empirically supported the importance of the role of asset variables in forming financial cycles.

While it is supported empirically, our decision to include the asset variable as a proxy for the financial cycle is also supported theoretically. Fluctuations in asset prices, which result in gyrations in the financial sector, will be source of real sector fluctuations according to the financial accelerator theory (Bernanke et al., 1999). This theory tries to explain the channels for the transmission of shocks from the financial sphere to the real economy, based on the value of collateral (Pouvelle et al., 2012).

According to this approach, economic agents' net worth is affected by movement in the asset's price, so that, the access by an economic agent to the financial system depends on the asset's price. In a condition where asset prices strongly increase, it gives more opportunities for households and firms to access credit. In turn, the rise in credit finances investment and consumption which further increase output and asset prices. The rise of output and asset prices will then intensify the initial increase in credit and investment. This mechanism is even more important in the case of asset price bubbles because when the bubble bursts loan losses are important and may cause an economic downturn. This mechanism is known in the literature as the financial accelerator mechanism (López, Tenjo, \& Zárate, 2014). In relation to this, Chaney, Sraer, \& Thesmar (2012) attempted to measure the collateral channels to the business sector, by estimating the effect of real estate prices on investment, and found that an increase in the collateral value by USD 1 is associated with an increase in the investment of land-holding firms by 6 cents. By accommodating asset variables, such as property and equity prices, along with the credit variable (credit growth) as the proxies of the financial cycle, this study can capture the phenomena of the financial cycle more comprehensively.

Moreover, unlike Antonakakis et al. (2015) who arbitrarily set up the number of windows in the rolling window estimation (50 quarters), we prefer to use the turning point analysis developed by Bry \& Boschan (1971) to get the proper number of windows representing the length of the business and financial cycles. The choice of the 50-quarters rolling window found in Antonakakis et al. (2015) cannot be applied automatically in our study, because there are 
differences in the characteristics of our objects (developing countries) compared to Antonakakis (G7 countries). Regarding this issue, Gonzalez, Lima, \& Marinho (2015) has found that cyclical trends in developing countries, both in the financial and business sectors, tend to be more volatile than those found in the developed counties. They generally last for around 4-7 years (Gonzalez et al., 2015). As consequence, the cyclical trend in the financial and business sectors in developing countries is also quicker, ranging for around $4-7$ years. By adopting the turning point analysis, we may find the number of windows more accurately and contextually relevant to capture the length of the business and financial cycles in the observed countries.

\section{METHOD, DATA, AND ANALYSIS}

\section{Methodology for Measuring Spillovers}

In line with Diebold and Yilmaz (2012), who developed the methodology proposed in Diebold and Yilmaz (2009), we utilize the generalized VAR framework to measure the spillover between variables. This approach allows us to identify the relative contribution of own variables shocks and other variables shocks to the forecast error variance for each variable in the VAR model which are calculated and shown in tabular form. The spillover index table provides a measure of the relative importance of the cross variance shares, or spillovers, and thus indicates the degree of interaction between the variables (Conefrey \& Cronin, 2015). Another advantage of using Diebold and Yilmaz (2012) is it is more informative because this method also allows us to capture the evolution of the spillovers' patterns over time by using a rolling window estimation. The starting point for the analysis is the following $P^{\text {th }}$ order, $K$-variable VAR (Antonakakis et al., 2015),

$$
y_{t}=\sum_{p=1}^{P} \Theta_{i} y_{t-i}+\varepsilon_{t}
$$

Where $y_{t}=\left(y_{1 t}, y_{2 t}, y_{3 t,} y_{4 t, \ldots . .} y_{k t}\right)$ is a vector of endogenous variables, $\Theta_{\mathrm{i}}, i=1, \ldots, \mathrm{P}$, are $\mathrm{K} \times \mathrm{K}$ parameter matrices and $\varepsilon_{\mathrm{t}} \sim(0, \Sigma)$ is a vector of disturbances that are independently distributed over time, $\mathrm{t}=1, \ldots . \mathrm{T}$ is the time index.

Critical to the dynamics of the system is the moving average representation of Model (1), which is given by $y_{t}=\sum_{j=0}^{\infty} A_{j} \varepsilon_{t-j}$, where the $\mathrm{K} \times \mathrm{K}$ coefficient matrices $A_{j}$ are recursively defined as $A_{j}=\Theta_{1} A_{j-1}+\Theta_{2} A_{j-2}+\cdots+$ $\Theta_{p} A_{j-p}$, where $A_{0}$ is the $\mathrm{K} \times \mathrm{K}$ identity matrix and $A_{j}=0$ for $j<0$.

In line with Diebold and Yilmaz (2012), we adopt the generalized VAR framework of Koop et al. (1996) and Pesaran et al. (1998), which allows us to have variance decompositions that are invariant to the variable's ordering. Based on this methodology, the H-step-ahead forecast error variance decomposition is (Antonakakis et al., 2015):

$$
\phi_{i j}(H)=\frac{\sigma_{j j}^{-1} \sum_{h=0}^{H-1}\left(e^{\prime} A_{h} \sum e_{j}\right)^{2}}{\sum_{h=0}^{H-1}\left(e^{\prime} A_{h} \sum A, h e_{i}\right)}
$$

Where $\Sigma$ is the (estimated) variance matrix of the error vector $\varepsilon . \sigma_{j j}$ the (estimated) standard deviation or the error term for the $j$ th equation and $e_{i}$ a selection vector with one as the $i$ th element and zero otherwise. This yields a $\mathrm{K} \times \mathrm{K}$ matrix $\phi(H)=\left[\phi_{i j}(H)\right]_{i, j=1, \ldots K}$, where each entry in this matrix shows the contribution of variable $j$ to the forecast error variance of variable $i$. To be noticed, the main diagonal elements contain the (own) contributions of shocks of the variable $i$ to its own forecast error variance, the off-diagonal elements provide the (cross) contributions of the other variables $j$ to the forecast error variance of variable $i$ (Antonakakis et al., 2015).

Because of the own and cross variables variance contribution shares do not sum to one under the generalized decomposition, each entry of the variance decomposition matrix should be 
normalized by its row sum (Antonakakis et al., 2015),

$$
\tilde{\phi}_{i j}(H)=\frac{\phi_{i j}(H)}{\sum_{j=1}^{K} \phi_{i j}(H)}
$$

with $\sum_{j=1}^{K} \tilde{\phi}_{i j}(H)=1$ and $\sum_{i, j=1}^{K} \tilde{\phi}_{i j}(H)=K$ by construction.

This ultimately allows us to define a total (volatility) spillover index as

$$
\begin{aligned}
T S(H) & =\frac{\sum_{i, j=1, i \neq j}^{K} \widetilde{\phi}_{i j}(H)}{\sum_{i, j=1}^{K} \widetilde{\phi}_{i j}(H)} \times 100 \\
& =\frac{\sum_{i, j=1, i \neq j}^{K} \widetilde{\phi}_{i j}(H)}{K} x 100
\end{aligned}
$$

Which indicates the average contribution of spillovers between all the observed variables to the total forecast error's variance.

Another advantage of this methodology is its flexibility which allows us to gain a more comprehensive insights by providing us with the calculation of directional spillovers, that is the directional spillovers earned by variable $i$ from all other variables $j$,

$$
\begin{aligned}
D S_{i \leftarrow j}(H) & =\frac{\sum_{j=1, j \neq i}^{K} \widetilde{\phi}_{i j}(H)}{\sum_{i, j=1}^{K} \widetilde{\phi}_{i j}(H)} \times 100 \\
& =\frac{\sum_{j=1, j \neq i}^{K} \widetilde{\phi}_{i j}(H)}{K} \times 100
\end{aligned}
$$

and the directional spillovers transferred by variable $i$ to all other variables $j$ as

$$
\begin{aligned}
D S_{i \rightarrow j}(H) & =\frac{\sum_{j=1, j \neq i}^{K} \widetilde{\phi}_{j i}(H)}{\sum_{i, j=1}^{K} \widetilde{\phi}_{j i}(H)} \times 100 \\
& =\frac{\sum_{j=1, j \neq i}^{K} \widetilde{\phi}_{j i}(H)}{K} \times 100
\end{aligned}
$$

By calculating these directional spillovers, we can decompose the total spillovers into those coming from (or to) a particular variable. This decomposition of the total spillovers is called the net spillover. For example, we can calculate the net spillover of variable $i$ to all other variables $j$ by subtracting Equation (6) with Equation (5). So that, in this case, we have the net spillover formula,

$$
N S_{i}=D S_{i \rightarrow j}(H)-D S_{i \leftarrow j}(H)
$$

The net spillover formula, as illustrated by Equation (7), contains information on how much market (variable) shares to the movement in other markets. It can be concluded that the spillover table shows how intense the interdependence between sectors (or variables) and because of its flexibility, it is possible to decompose the spillover effects based on their source and recipients.

\section{Turning Point Analysis for Setting Up the Number of Windows Used}

One important aspect to be aware of when doing a rolling window estimation in Diebold and Yilmaz (2012) is the number of windows used. Antonakakis et al. (2015) set it up arbitrarily by using 50-quarters. According to Antonakakis et al. (2015), these periods are assumed to be long enough to portray the whole of the business cycle and the financial cycle. Meanwhile, Conefrey and Cronin (2015) developed a robustness test by comparing two different moving windows. In relation to this concern, they chose the one that can describe spillovers better as indicated by the smaller number of explosive roots. In our present study, the number of windows will be set up trough a turning point analysis as proposed by Harding and Pagan (2002), who developed the BB algorithm in Bry and Boschan (1971). This method requires the duration of a complete cycle and of each phase to be at least five quarters and two quarters respectively. Specifically, a peak in a quarterly series $y_{t}$ occurs at time $t$ if (Claessens et al., 2011)

$$
\begin{array}{r}
\left\{\left[\left(y_{t}-y_{t-2}\right)>0,\left(y_{t}-y_{t-1}\right)>0\right]\right. \\
\text { and } \left.\left[\left(y_{t+2}-y_{t}\right)<0,\left(y_{t+1}-y_{t}\right)<0\right]\right\}
\end{array}
$$

Similarly, a cyclical trough occurs at time $t$ if

$$
\left\{\left[\left(y_{t}-y_{t-2}\right)<0,\left(y_{t}-y_{t-1}\right)<0\right]\right.
$$


and $\left.\left[\left(y_{t+2}-y_{t}\right)>0,\left(y_{t+1}-y_{t}\right)>0\right]\right\}$

By applying this method for setting up the number of windows to be used in a rolling window estimation, we adopt a more standardized and robust methodology, so that compared to Antonakakis et al. (2015), we have a stronger foundation rather than arbitrarily setting it which might be highly subjective.

Table 1 shows the length of the cycle for the business sectors in all the sample countries. We find that, in terms of the business cycle, the length of the complete cycle is no more than 30quarters. We also discover the same result in credit, property and equity cycles in which the length of the complete cycle in each market's segment is no more than 30 quarters. Based on this result, for the rolling window estimation, we use 30-quarters as our number of windows in analyzing the time-varying relationship between the observed variables.

Table 1. Turning Point Analysis for Business Cycle

\begin{tabular}{|c|c|c|c|c|c|c|c|c|c|c|c|}
\hline \multicolumn{6}{|c|}{ Indonesia } & \multicolumn{6}{|c|}{ Malaysia } \\
\hline Peaks & P-to-P & T-to-P & Troughs & T-to-T & P-to-T & Peaks & P-to-P & T-to-P & Troughs & T-to-T & P-to-T \\
\hline & & & 1986:01 & & & 1986:02 & & & $1987: 02$ & & 4 \\
\hline 1988:03 & & 10 & 1991:02 & 21 & 11 & 1988:01 & 7 & 3 & 1989:03 & 9 & 6 \\
\hline 1991:04 & 13 & 2 & 1993:01 & 7 & 5 & 1990:01 & 8 & 2 & 1991:02 & 7 & 5 \\
\hline 1994:04 & 12 & 7 & 1995:04 & 11 & 4 & 1995:01 & 20 & 15 & 1996:02 & 20 & 5 \\
\hline 1996:04 & 8 & 4 & 1998:04 & 12 & 8 & 1996:04 & 7 & 2 & 1998:04 & 10 & 8 \\
\hline 1999:04 & 12 & 4 & 2001:04 & 12 & 8 & 2000:01 & 13 & 5 & 2001:04 & 12 & 7 \\
\hline 2003:01 & 13 & 5 & 2006:01 & 17 & 12 & 2002:03 & 10 & 3 & 2003:01 & 5 & 2 \\
\hline 2007:01 & 16 & 4 & 2009:03 & 14 & 10 & 2004:01 & 6 & 4 & 2005:02 & 9 & 5 \\
\hline 2011:03 & 18 & 8 & 2012:03 & 12 & 4 & 2006:02 & 9 & 4 & 2007:01 & 7 & 3 \\
\hline \multirow[t]{3}{*}{ 2014:03 } & 12 & 8 & & & & 2008:01 & 7 & 4 & 2009:01 & 8 & 4 \\
\hline & & & & & & 2010:01 & 8 & 4 & 2010:03 & 6 & 2 \\
\hline & & & & & & 2012:04 & 11 & 9 & & & \\
\hline \multicolumn{6}{|c|}{ Thailand } & \multicolumn{6}{|c|}{ Singapore } \\
\hline \multirow[t]{2}{*}{ Peaks } & P-to-P & T-to-P & Troughs & T-to-T & P-to-T & Peaks & P-to-P & T-to-P & Troughs & T-to-T & P-to-T \\
\hline & & & $1985: 03$ & & & & & & 1989:03 & & \\
\hline 1986:03 & & 4 & 1987:03 & 8 & 4 & 1990:01 & & 2 & 1992:01 & 10 & 8 \\
\hline 1988:04 & 9 & 5 & 1990:01 & 10 & 5 & 1993:02 & 13 & 5 & 1993:04 & 7 & 2 \\
\hline 1991:01 & 9 & 4 & 1991:04 & 7 & 3 & 1994:03 & 5 & 3 & 1995:01 & 5 & 2 \\
\hline 1992:04 & 7 & 4 & 1994:03 & 11 & 7 & 1996:01 & 6 & 4 & 1997:01 & 8 & 4 \\
\hline 1996:01 & 13 & 6 & 1998:02 & 15 & 9 & 1997:03 & 6 & 2 & 1998:03 & 6 & 4 \\
\hline 1999:04 & 15 & 6 & 2001:04 & 14 & 8 & 1999:03 & 8 & 4 & 2000:02 & 7 & 3 \\
\hline 2003:01 & 13 & 5 & 2005:04 & 16 & 11 & 2000:04 & 5 & 2 & 2001:03 & 5 & 3 \\
\hline 2007:04 & 19 & 8 & 2009:01 & 13 & 5 & 2002:03 & 7 & 4 & 2003:02 & 7 & 3 \\
\hline 2010:01 & 9 & 4 & 2011:04 & 11 & 7 & 2004:02 & 7 & 4 & 2005:01 & 7 & 3 \\
\hline \multirow[t]{4}{*}{ 2012:04 } & 11 & 4 & 2014:01 & 9 & 5 & 2006:02 & 8 & 5 & 2009:01 & 16 & 11 \\
\hline & & & & & & 2010:02 & 16 & 5 & 2011:02 & 9 & 4 \\
\hline & & & & & & 2011:04 & 6 & 2 & 2013:01 & 7 & 5 \\
\hline & & & & & & 2014:01 & 9 & 4 & & & \\
\hline
\end{tabular}

Source: Data Processed (1985 quarter 1-2015 quarter 4) 


\section{Data Description}

The data used in this study includes the index of industrial production's growth, the credit growth, the property prices index growth, and the equity price index growth. All data are at a quarterly frequency. This frequency is chosen because of the limited availability of data, especially for the property price index's data which is only available quarterly. Even so, from previous studies, it is found that quarterly data is capable of capturing the cyclical trend for each variable. It can identify and document the features of the financial and business cycles adequately (Claessens et al., 2011).

Operationally, as we mentioned earlier credit growth, the index of property prices growth, and the equity price index growth will be used as proxies for the financial cycle. Meanwhile, the index of industrial production's growth is going to be used as a proxy for the business cycle. To have the year-on-year growth, we calculate the fourth differences of the natural logarithms of each variable.

Before discussing the main result of this study about the spillovers between variables within and across countries, the descriptive statistics of the year-on-year growth of each variable is represented in Table 2. The countries average of IIP, BC, PP and SI growth lies within [5.3, 6.0 percent] for IIP, [6.0, 8.2 percent] for $\mathrm{BC},[3.1,8.0$ percent] for PP and [3.9, 13.3 percent] for SI respectively. The somewhat high standard deviation in all the sample countries indicates that there is a relatively high variation for each variable.

Tabel 2. Data and Source of Data

\begin{tabular}{clccc}
\hline Country & \multicolumn{1}{c}{ Variable } & Name of Variable & Years & Source \\
\hline \multirow{5}{*}{ Indonesia } & Industrial Production & BCIna & & \\
& Credit & PPIna & $1984-2015$ & Datastream \\
& Property Price & SIIna & & \\
& Equity Price & IIPMas & & \\
& Industrial Production & BCMas & & \\
& Credit & PPMas & $1984-2015$ & Datastream \\
Malaysia & Property Price & SIMas & & \\
& Equity Price & & & \\
& Industrial Production & IIPTa & & \\
& Credit & BCTha & & \\
& Property Price & PPTha & $1984-2015$ & Datastream \\
& Equity Price & SITha & & \\
& Industrial Production & IIPSin & & \\
& Credit & BCSin & \multirow{2}{*}{$1988-2015$} & Datastream \\
& Property Price & PPSIn & & \\
\hline
\end{tabular}


Table 3. Descriptive Statistics

\begin{tabular}{lcccrrrrr}
\hline & IIPIna & \multicolumn{1}{c}{ BCIna } & \multicolumn{1}{c}{ PPIna } & \multicolumn{1}{c}{ SIIna } & \multicolumn{1}{c}{ IIPMal } & \multicolumn{1}{c}{ BCMal } & \multicolumn{1}{c}{ PPMal } & \multicolumn{1}{c}{ SIMal } \\
\hline Mean & 0.055 & 0.072 & 0.080 & 0.133 & 0.060 & 0.060 & 0.042 & 0.052 \\
Std Dev & 0.103 & 0.244 & 0.086 & 0.364 & 0.103 & 0.117 & 0.028 & 0.276 \\
Max & 0.272 & 0.422 & 0.579 & 1.307 & 0.478 & 0.280 & 0.115 & 0.683 \\
Min & -0.407 & -1.161 & -0.006 & -0.706 & -0.196 & -0.502 & -0.002 & -0.861 \\
\hline & IIPTha & BCTha & \multicolumn{1}{c}{ PPTha } & \multicolumn{1}{c}{ SITha } & \multicolumn{1}{c}{ IISin } & \multicolumn{1}{c}{ BCSin } & \multicolumn{1}{c}{ PPSin } & \multicolumn{1}{c}{ SISin } \\
\hline Mean & 0.056 & 0.061 & 0.031 & 0.077 & 0.053 & 0.082 & 0.052 & 0.039 \\
Std Dev & 0.083 & 0.151 & 0.049 & 0.350 & 0.095 & 0.095 & 0.149 & 0.256 \\
Max & 0.347 & 0.280 & 0.200 & 0.987 & 0.372 & 0.320 & 0.385 & 0.766 \\
Min & -0.257 & -0.565 & -0.207 & -0.861 & -0.272 & -0.110 & -0.416 & -0.732 \\
\hline
\end{tabular}

Source: Data Processed (1985 quarter 1-2015quarter 4)

\section{Results}

4.1. Spillovers between Variables within
Countries

In Table 4, we show estimates of the spillover indices for each country based on 10-quarters ahead of the forecast error variance's decomposition. To be noticed, the $i j^{\text {th }}$ entry is the estimated contribution to the forecast error variance of variable $i$ coming from innovations to variable $j$. The diagonal elements $(i=j)$ measure own-variable spillovers within countries, while the off diagonal elements $(i \neq j)$ portray cross variable spillovers between the observed variables. The total spillover index is approximately equal to the sum of the offdiagonal entries relative to the total column including diagonals that is expressed in percentage points (Antonakakis et al., 2015; Diebold \& Yilmaz, 2012).

Considering the information in Table 4, we find that the magnitude of the spillovers between variables is diverse in each of the ASEAN-4 countries. The total spillovers are relatively high in Singapore, Indonesia and Thailand, with total spillover indices of 45.1 percent, 36.2 percent, and 21.5 percent respectively. In Malaysia, the total spillovers are found to be smaller at only 11.7 percent. However, with the value being more than 10 percent, we can conclude that the total spillovers among the observed variables in
Malaysia are not low. In contrast, the estimated value is slightly higher. Even so, compared to the others, the total spillovers in Malaysia are indeed relatively smaller, suggesting that credit, property, and equity price growth are not as closely linked compared to the three other countries.

Concerning the directional spillovers, we find that the trend of spillovers shown by the sample countries has displays a similar pattern, in terms of the role of the real sectors across the countries and tend to act as a receiver of shocks. As indicated by the value of the "directional to others" that is less than the value of the "directional from others". In other words, relative to the dynamics of the financial sectors, the business sectors in all the countries tend to be more passive.

Related to the above, equity cycles are found to be the variable that has the highest spillovers to others in Singapore, Malaysia, and Thailand, as indicated in its value of "directional to others". Differing from the others, in Indonesia, this role is dominantly taken by the credit cycle. This finding is not surprising since, compared to the other three countries, the financial market in Indonesia experiences less growth. For this reason, it makes sense that in Indonesia the equity cycle has a relatively weak interaction with the other variables compared to the credit cycle. 
Table 4. Spillovers Table of Observed Variables Within the ASEAN-4 Countries

\begin{tabular}{|c|c|c|c|c|c|}
\hline \multicolumn{6}{|c|}{ Indonesia } \\
\hline \multicolumn{6}{|c|}{ From (j) } \\
\hline To (i) & IIPINA & BCINA & PPINA & SIINA & From Others \\
\hline IIPINA & 56.4 & 32.4 & 9.4 & 1.8 & 43.6 \\
\hline BCINA & 3.5 & 87.5 & 6.1 & 2.9 & 12.5 \\
\hline PPINA & 5.2 & 60.1 & 33.9 & 0.8 & 66.1 \\
\hline SIINA & 2.1 & 18.1 & 2.7 & 77.2 & 22.8 \\
\hline Directional to Others & 10.7 & 100.5 & 18.1 & 5.6 & 144.9 \\
\hline Directional Including Own & 67.1 & 198.1 & 52.0 & 82.6 & $36.2 \%(\mathrm{TSI})$ \\
\hline \multicolumn{6}{|c|}{ Malaysia } \\
\hline \multicolumn{6}{|c|}{ From (j) } \\
\hline To (i) & IIPMAS & BCMAS & PPMAS & SIMAS & From Others \\
\hline IIPMAS & 79.9 & 3.5 & 2.3 & 14.3 & 20.1 \\
\hline BCMAS & 3.3 & 92.1 & 0.8 & 3.8 & 7.9 \\
\hline PPMAS & 0.5 & 0.5 & 93.1 & 5.9 & 6.9 \\
\hline SIMAS & 1.2 & 10.0 & 0.8 & 88.0 & 12.0 \\
\hline Directional to Others & 5.0 & 14.0 & 4.0 & 24.0 & 47.0 \\
\hline Directional Incluing Own & 84.9 & 106.1 & 97.0 & 112.0 & $11.7 \%(\mathrm{TSI})$ \\
\hline \multicolumn{6}{|c|}{ Thailand } \\
\hline \multicolumn{6}{|c|}{ From (j) } \\
\hline To (i) & IIPTHA & BCTHA & РPТНA & SITHA & From Others \\
\hline IIPTHA & 71.9 & 12.4 & 5.1 & 10.6 & 28.1 \\
\hline ВСТНА & 0.7 & 75.6 & 5.8 & 18.0 & 24.4 \\
\hline PРТНA & 0.9 & 7.2 & 90.0 & 1.9 & 10.0 \\
\hline SITHA & 5.9 & 7.9 & 9.8 & 76.4 & 23.6 \\
\hline Directional to Others & 7.5 & 27.5 & 20.7 & 30.5 & 86.1 \\
\hline Directional Including Own & 79.4 & 103.1 & 110.7 & 106.9 & $21.5 \%(\mathrm{TSI})$ \\
\hline \multicolumn{6}{|c|}{ Singapore } \\
\hline \multicolumn{6}{|c|}{ From (j) } \\
\hline To (i) & IIPSIN & BCSIN & PPSIN & SISIN & From Others \\
\hline IIPSIN & 59.7 & 2.0 & 10.1 & 28.2 & 40.3 \\
\hline BCSIN & 8.5 & 43.4 & 31.0 & 17.0 & 56.6 \\
\hline PPSIN & 6.6 & 5.4 & 51.6 & 36.5 & 48.4 \\
\hline SISIN & 4.8 & 3.1 & 27.3 & 64.8 & 35.2 \\
\hline Directional to Others & 20.0 & 10.5 & 68.4 & 81.6 & 180.4 \\
\hline Directional Including Own & 79.6 & 53.9 & 120.0 & 146.4 & $45.1 \%(\mathrm{TSI})$ \\
\hline
\end{tabular}

Source : Data Processed (1985q1-2015q4)

Note: TSI is abbreviation for Total Spillover Index

Even though the average calculation of financial and business cycle spillovers gives a good insight into financial and business cycle's interdependence, it may mask interesting findings about the movement of spillovers because of the secular features of the financial (represented by the cycle of three different markets) and business cycles. Regarding this concern, we are very keen to analyze how total and net spillovers change over time. By doing so, we may identify whether they are stirred by particular economic events, such as an economic crisis or a recession. We do an estimation to the Eq.(1) using 30-quarter rolling window and 
obtain the variance decomposition and spillover indices in a time-varying fashion. The estimation results are shown in Figure 1 below.

Although there are some variations, the total spillover indices in all the countries are found to be relatively high. Yet, the most interesting fact found from the figure of the time-varying total spillovers above is that around the beginning or in the middle of the crises, both in the Asian crisis and the US crisis, the total spillover indices in all the countries tended to become higher. This means that the relationship between the business cycle and the financial cycle becomes significantly stronger during this period. This also indicates that the credit, property and equity cycles (as a predictor of the financial cycle) are exceptionally strongly involved in both crises.
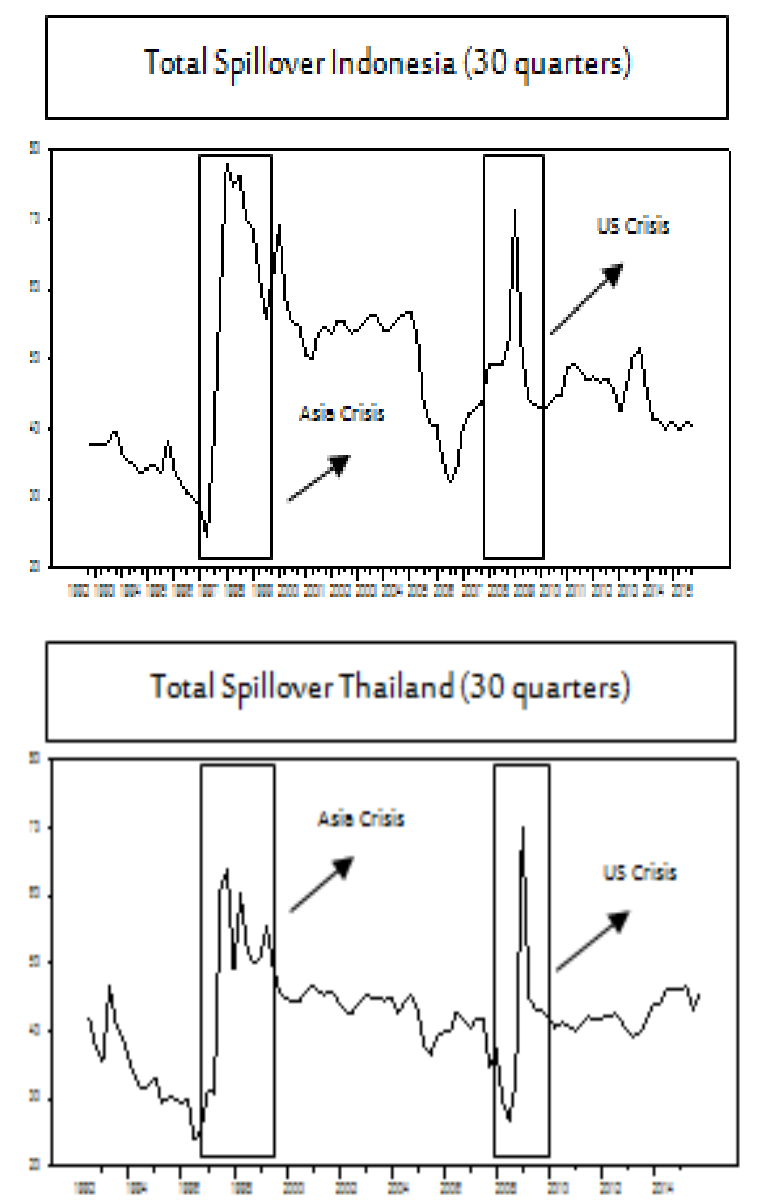

Figure 2 indicates the time-varying net spillovers from the observed variables. By looking at the dynamism over time, we can explicitly identify the link between the variables during crises periods. Interestingly, the role of the business cycle, which according to Table 4 is more passive and tends to act as a receiver of shocks in all the countries, when we take the rolling sample estimation into account, is found to be the leading transmitter at the outset of the Asian crisis. But net spillovers quickly turn into a negative, stressing that for most of the crisis period, the financial cycle, whether caused by a single cycle or a combination of the credit, property and equity cycles, replaced real economic development as the dominant transmitter.
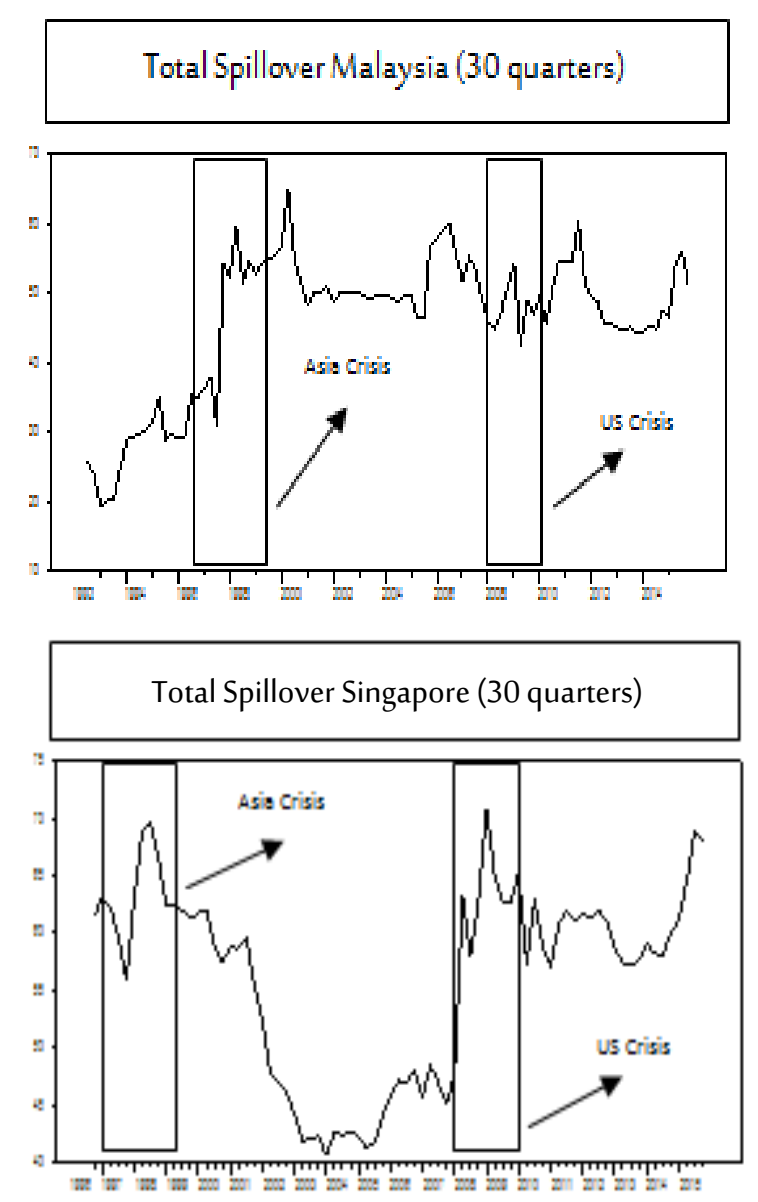

Figure 1. Total spillover of variables within ASEAN-4 countries.

Notes: Plots of moving total spillover estimated using 30-quarters rolling window. 
Indonesia
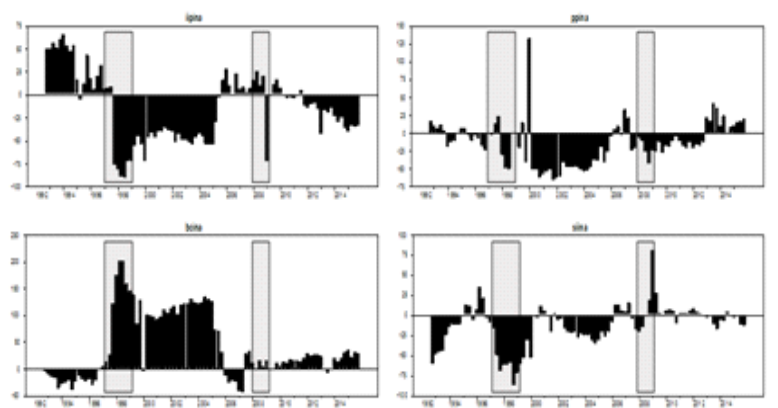

Thailand
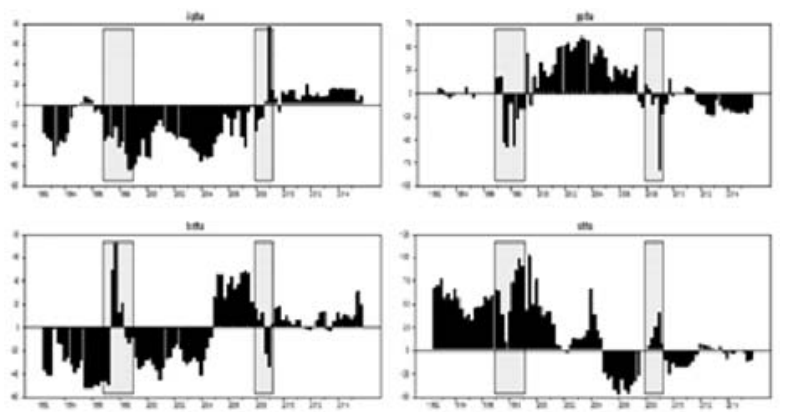

Malaysia
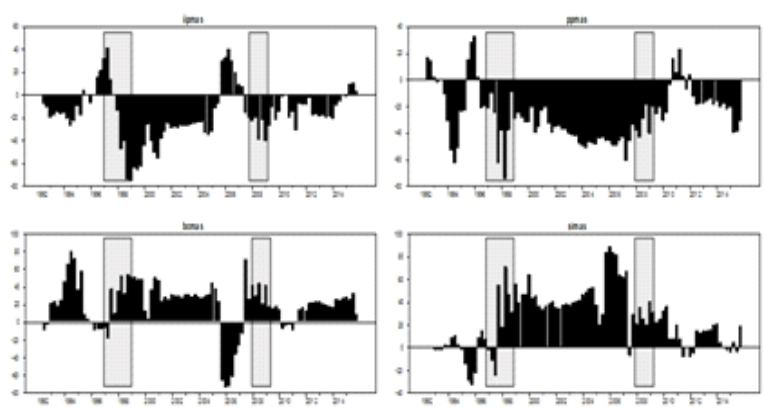

Singapore
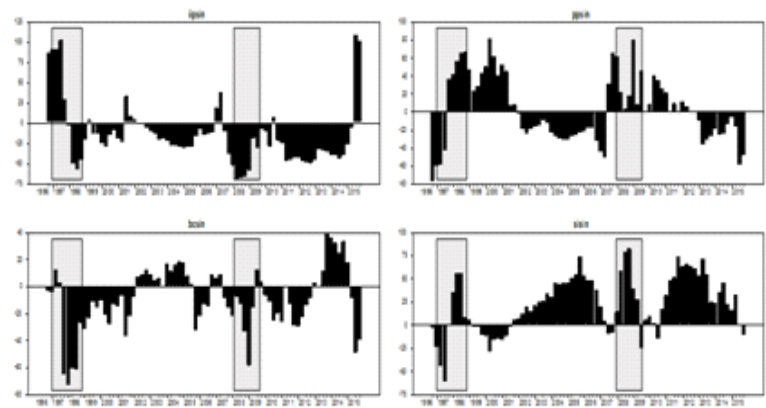

Figure 2. Net spillover of variables within ASEAN-4 countries.

Notes: Plots of moving net spillovers estimated using 30-quarters rolling window. Positive (negative) values indicate the role of the variable whether as a transmitter or a receiver of shocks. Grey bars denote Asian crises and US financial crises. NB: the order of variables shown in the pictures: IIP, PP (above - right to left) and BC, SI (below - right to left).

Table 5. Stability Check Condition

\begin{tabular}{crcr}
\hline & \multicolumn{3}{c}{ Within Countries Analysis } \\
\hline Indonesia & \multicolumn{3}{c}{ Malaysia } \\
\hline Eigen Value & Modulus & Eigen Value & Modulus \\
$0.659+0.484$ & 0.817 & 0.911 & 0.911 \\
$0.659-0.484$ & 0.817 & 0.082 & 0.082 \\
0.785 & 0.785 & $0.742+0.080$ & 0.745 \\
0.731 & 0.731 & $0.742-0.080$ & 0.745 \\
$0.659+0.111$ & 0.669 & & \\
$0.659-0.111$ & 0.669 & & \\
$-0.038+0.182$ & 0.186 & & \\
$-0.038-0.182$ & 0.186 & & Singapore \\
\hline Thailand & & & 0.848 \\
\hline Eigen Value & Modulus & Eigen Value & 0.848 \\
0.832 & 0.832 & $0.744+0.408$ & 0.744 \\
0.654 & 0.654 & $0.744-0.408$ & 0.744 \\
0.596 & 0.596 & $0.744+0.027$ & 0.442 \\
0.462 & 0.462 & $0.744-0.027$ & 0.442 \\
& & $0.385+0.216$ & 0.276 \\
& & $0.385-0.216$ & 0.276 \\
\hline
\end{tabular}

Source: Data Processed (1985 quarter 1-2015 quarter 4)

Notes:All the Eigenvalues lie inside the unit circle. 
A similar pattern is also found in the recent global financial crisis. However, even though the business cycle is still acting as the important variable in transmitting shocks during the onset of the crisis in the majority of countries, the configuration of variables acting as the dominant transmitter is seen to be more complex. With regard to this, the business cycle is not the only transmitter of the crisis, but it is also accompanied by the financial cycle from the beginning of the crisis. This indicates that the interaction of variables in the global financial crisis was more complicated compared to the Asian crisis in our sample countries. Through most of the crisis period, the financial cycle is the dominant transmitter in Malaysia and Singapore. But in Indonesia and Thailand, we find different tendencies, in terms of the role of the business sectors that persistently become the transmitters of the crisis for some of the time during the period of the crisis.

Thus, in the case of the Asian crisis, the business sector played a dominant role in the early stages of the crisis in the ASEAN-4 countries. Meanwhile, as the crisis deepened, the financial sector tended to take over as the dominant source of spillovers. This indicates that there is an interchanging role played between both sectors in times of crisis.

To check whether the results are credible or not, we test the stability of the models used to estimate the spillovers by calculating the value of the roots of the characteristic polynomial. As indicated by the value of the moduli that less than 1 , no root lies outside the unit circle. Based on this finding, we may conclude that all the models are stable, therefore, it can be concluded that the result obtained from the models' estimations is valid.

\subsection{Spillovers between Variables Across}

Countries

In this section, we try to develop the analysis by identifying the spillovers between variables across the countries. As it seems logical to think that the dynamism of the financial sector in one particular country may influence not only the financial sectors of other countries but also the business sectors, so that we estimate a VAR with observed variables for each country. In this part we exclude Singapore because of constrains on the data's availability. Based on a twelvevariable VAR, the estimation results of the spillovers are shown in Table 6 below.

Considering the information tabulated in Table 6, it can be seen that the total spillover index shows a value of 58.6 percent, which appears to be quantitatively large in average. This value indicates that approximately 60 percent of the forecast errors' variance of the variables comes from spillovers. Hence, spillovers are important in the dynamics of each observed variable.

The constellations of the regional spillovers between variables in the ASEAN-3 countries show that the credit cycle in Thailand is a dominant transmitter of shocks regionally, as it has the highest value directionally to the others with 142.2 percent and 76 percent respectively. In addition, our results indicate that Thailand's credit cycle and Malaysia's equity cycle are important for the appreciation of spillovers within and between the real and financial sectors across the countries. This finding has stressed the crucial role played by the financial sectors in generating the business sectors. Interestingly, the role played is diverse in nature showing that there is a complexity regarding the interaction between both sectors (Jordà et al., 2013; Antonakakis et al., 2015). 
Table 6. Spillover Table of Observed Variables Between ASEAN-3 Countries

\begin{tabular}{|c|c|c|c|c|c|c|c|c|c|c|c|c|c|}
\hline \multicolumn{14}{|c|}{ From (j) } \\
\hline To (i) & IIPINA & BCINA & PPINA & SIINA & IIPMAS & BCMAS & PPMAS & SIMAS & IIPTHA & BCTHA & PPTHA & SITHA & From Others \\
\hline IIPINA & 34.8 & 9.1 & 8.5 & 0.9 & 6.4 & 6.9 & 0.4 & 6.4 & 0.9 & 13.8 & 4.3 & 7.4 & 65.1 \\
\hline BCINA & 3.4 & 27.8 & 3.9 & 0.4 & 7.9 & 12.4 & 0.1 & 6.9 & 0.3 & 25.9 & 0.4 & 10.4 & 72.2 \\
\hline PPINA & 4.3 & 19.7 & 15.3 & 0.4 & 6.1 & 10.2 & 0.6 & 13.4 & 0.3 & 17.7 & 6.5 & 5.6 & 84.7 \\
\hline SIINA & 4.2 & 6.2 & 2.5 & 32.2 & 1.2 & 2.2 & 1.6 & 26.1 & 4.8 & 10.8 & 2.3 & 5.9 & 67.8 \\
\hline IIPMAS & 4.5 & 2.8 & 3.3 & 5.4 & 58.9 & 1.3 & 1.9 & 4.3 & 2.8 & 3.0 & 1.3 & 10.4 & 41.1 \\
\hline BCMAS & 1.5 & 12.7 & 7.2 & 0.2 & 7.4 & 38.2 & 0.1 & 0.9 & 0.7 & 28.0 & 0.8 & 2.2 & 61.8 \\
\hline PPMAS & 2.2 & 0.4 & 1.4 & 4.8 & 1.1 & 0.3 & 68.3 & 8.4 & 0.8 & 2.8 & 3.6 & 5.8 & 31.7 \\
\hline SIMAS & 1.0 & 8.4 & 6.2 & 3.6 & 4.3 & 3.7 & 0.5 & 48.1 & 1.8 & 13.4 & 3.3 & 5.6 & 51.9 \\
\hline IIPTHA & 2.1 & 7.7 & 3.7 & 2.7 & 5.0 & 5.1 & 1.9 & 7.3 & 48.4 & 9.7 & 1.7 & 4.7 & 51.6 \\
\hline BCTHA & 6.7 & 6.6 & 10.4 & 0.8 & 10.6 & 11.5 & 0.5 & 1.9 & 0.3 & 33.8 & 0.5 & 16.5 & 66.2 \\
\hline PPTHA & 6.5 & 4.8 & 4.1 & 2.9 & 4.0 & 2.4 & 0.2 & 4.6 & 0.8 & 7.9 & 54.7 & 7.3 & 45.4 \\
\hline SITHA & 4.0 & 6.9 & 2.1 & 2.1 & 3.0 & 1.7 & 1.1 & 29.8 & 1.2 & 9.3 & 2.8 & 35.9 & 64.1 \\
\hline $\begin{array}{c}\text { Directional to } \\
\text { Others }\end{array}$ & 40.6 & 85.4 & 53.5 & 24.2 & 57.0 & 57.7 & 9.0 & 110.1 & 14.6 & 142.2 & 27.5 & 81.9 & 703.6 \\
\hline $\begin{array}{c}\text { Directional } \\
\text { Including Own }\end{array}$ & 75.5 & 113.2 & 68.8 & 56.4 & 115.9 & 95.9 & 77.2 & 158.2 & 63.0 & 176.0 & 82.1 & 117.8 & $\begin{array}{c}58.6 \% \\
\text { (Total Spillover Index) }\end{array}$ \\
\hline
\end{tabular}

Souce: Data Processed (1985 quarter 1-2015 quarter 4)

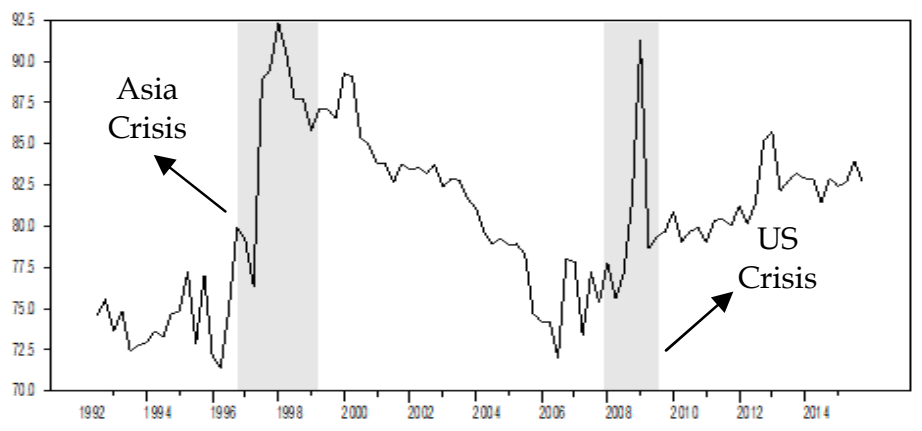

Figure 3. Total spillover between variables across the countries.

Notes: Plots of moving total spillover estimated using 30-quarters rolling window. Gray shading denotes Asia and US financial crisis.
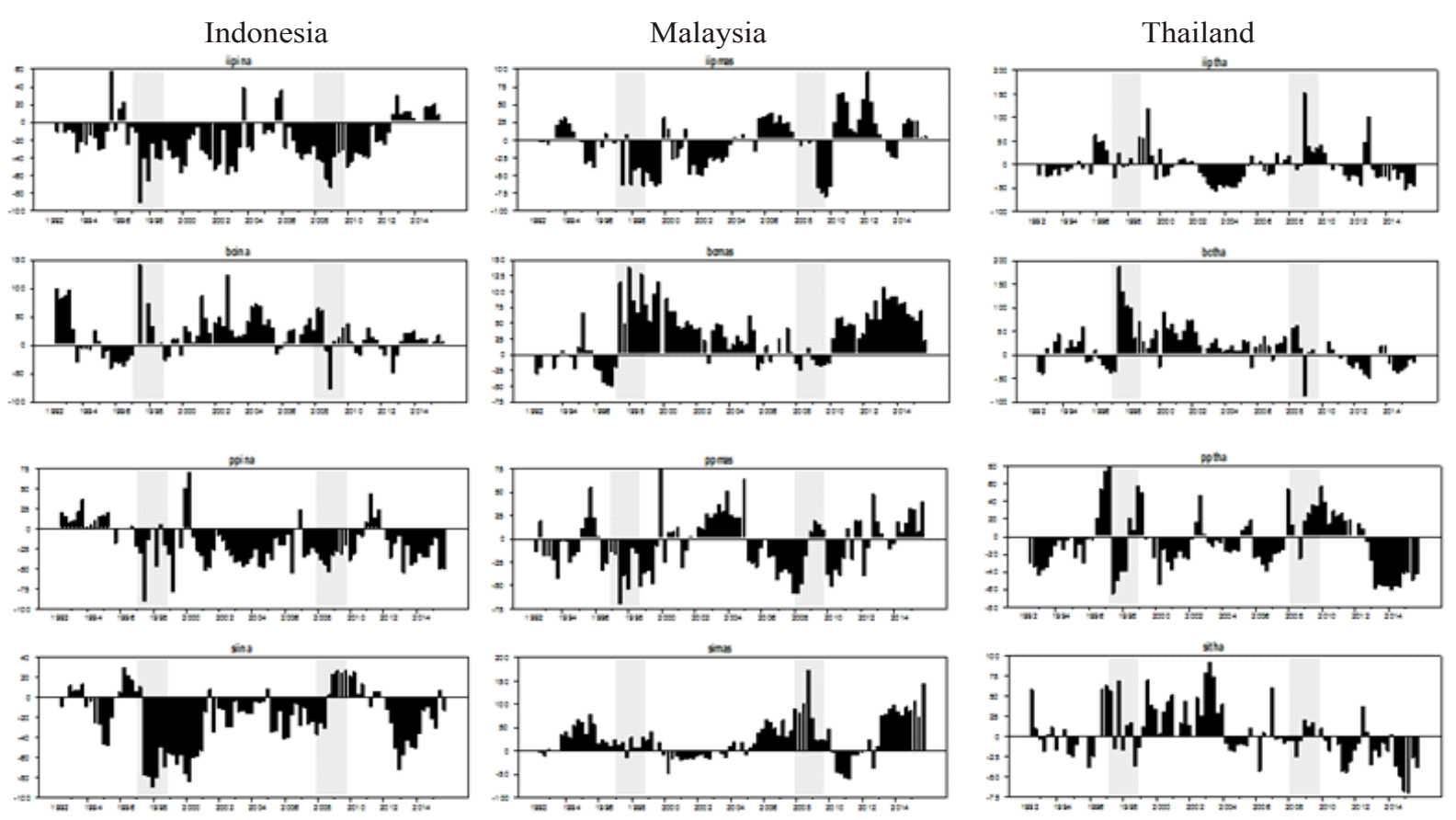

Figure 4. Net spillover between variables across countries.

Notes: Plots of moving net spillover estimated using 30-quarters rolling window. 
Concentrating our attention on the movement of total spillovers across the ASEAN3 countries over the period of the analysis, we find that the total spillovers between the observed variables, despite there being some fluctuations, tended to be high during the period of the analysis. They become significantly higher and reached a peak during particular economic episodes, such as the Asian crisis and the US financial crisis. Our results are consistent with the findings of Claessens et al. (2011), Jordà et al. (2013) and Antonakakis et al. (2015) by showing a negative correlation between financial turbulence and recession in the real sector.

Table 7. Stability Check Condition

\begin{tabular}{cc}
\hline \multicolumn{2}{c}{ Across Countries Analyses } \\
\hline Eigen Values & Modulus \\
$0.869+0.028 \mathrm{i}$ & 0.869 \\
$0.869-0.028 \mathrm{i}$ & 0.869 \\
$0.821+0.241 \mathrm{i}$ & 0.856 \\
$0.821-0.241 \mathrm{i}$ & 0.856 \\
0.813 & 0.813 \\
$0.702+0.162 \mathrm{i}$ & 0.720 \\
$0.702-0.162 \mathrm{i}$ & 0.720 \\
$0.624+0.086 \mathrm{i}$ & 0.630 \\
$0.624-0.086 \mathrm{i}$ & 0.630 \\
$0.508+0.084 \mathrm{i}$ & 0.515 \\
$0.508-0.084 \mathrm{i}$ & 0.515 \\
0.147 & 0.147 \\
\hline
\end{tabular}

Source: Data Processed (1985 quarter 1-2015 quarter 4) Notes: All the Eigenvalues lie inside the unit circle.

Considering Figure 4 which shows the timevarying net directional spillovers among the observed variables, the result that we found in the regional scope is basically in line with the result of the within countries analysis. It can briefly be seen that the business cycle, for part of the time during the analysis period, at the onset or during the crisis period, appears to be the dominant transmitter, but most of the time during the analysis the role of the regional transmitter of shocks is taken by the financial cycle. Specifically, we find that the role of the credit cycle in ASEAN-3 countries is significant in magnifying and amplifying the shocks to the real and financial sectors across countries.

Applying the same procedure to check the stability of the models, we find that the model used to estimate the spillovers between the observed variables across countries has been proven to be stable. As indicated by the values of the moduli which are less than 1 and show that no roots lie outside the unit circle. This means that the VAR model has satisfied the stability precondition, so that we may conclude that the result from the across countries model estimation is valid.

\section{CONCLUSION}

In this research, we analyze the time-varying relationship between the financial and business sectors in the ASEAN-4 countries, using the spillover index of Diebold and Yilmaz (2012). In principle, this method is very suited to accommodate the potential multidirectional spillovers of shocks between the observed variables including the index of industrial production's growth, the credit growth, the index of property prices' growth, and the equity price index's growth.

Related to these concerns, we find several fascinating facts that are in line with the existing studies. First, we discover that the magnitude and direction of the spillover effects move in a rather diversified manner across the sample countries. Secondly, the relationship between the financial and business sectors significantly increases during the crisis period. This indicates a negative correlation between financial crises and economic recessions (Claessens et al., 2011; Jordà et al., 2013; Antonakakis et al., 2015). Thirdly, on average, we find that relative to the financial sector, the business sector tended to be more passive during the period of our analysis. 
In contrast, the financial cycles that happened in the financial sector were primarily acting as the transmitters of the shocks. The importance of the role of the financial sector in driving the dynamics of the business sector which is found in this study is consistent with Claessens et al. (2011); Baur (2012); Aizenman et al. (2013). Fourth, we find that the credit cycle in Thailand, as one of the proxies for the financial cycle, is the leading regional transmitter of shocks to the real and especially to the financial sectors of other countries. In terms of the spillovers effect across countries, we find that the role of the credit cycle in the ASEAN-3 countries is significant in magnifying and amplifying the shocks to the real and financial sectors across countries.

Furthermore, we also find that in ASEAN-4 countries, the business sector takes a relatively dominant role in the early stages of the crisis, in the case of the Asian Crisis. However, once the crisis deepens, the financial sector tends to become the dominant source of spillovers. A similar tendency is also found in the case of the US financial crisis. Yet, in the latter case, this study discovered a more complicated configuration of spillovers from the observed variables. With regard to this, the business cycle is not the only transmitter of the crisis, but it had also been accompanied by the financial cycle since the beginning of the crisis. This indicates that the interaction of variables in the global financial crisis is more complicated compared to the Asian crisis in our sample countries.

\section{LIMITATION AND SUGGESTION}

Future research may include some developed countries that have become the major partners of the ASEAN countries in the international economy, so that, the mechanism for the transmission of spillovers between the financial sector and business sector can be analyzed more optimally.

\section{REFERENCES}

Aizenman, J., Pinto, B., \& Sushko, V. (2013). Financial sector ups and downs and the real sector in the open economy: Up by the stairs, down by the parachute. Emerging Markets Review, 16, 1-30.

Almekinders, G., Fukuda, S., Mourmouras \& A., Zhou, J. (2015). ASEAN financial integration (No. 15-34). International Monetary Fund.

Antonakakis, N., Breitenlechner, M., \& Scharler, J. (2015). Business cycle and financial cycle spillovers in the G7 countries. The Quarterly Review of Economics and Finance, 58, 154-162.

Apostoaie, C. M., \& Percic, S. (2014). Credit cycles and business cycles in twenty EU economies. Procedia Economics and Finance, 15, 1055-1064.

ASEAN Statistic. (2016). ASEAN statistic yearbook 2016. Jakarta, The ASEAN Secretariat.

Azis, I. J. (2013). The capital market in the context of financial safety nets. Oxford, Oxford University Press.

Baur, D. G. (2012). Financial contagion and the real economy. Journal of Banking \& Finance, 36(10), 2680-2692.

Bernanke, B. S., Gertler, M., S. Gilchrist (1999). Handbook of macroeconomics: The financial accelerator in a quantitative business cycle framework. Amsterdam: Elsevier Science.

Bry, G., Boschan, G. (1971). Cyclical analysis of time series: Selected procedures and computer programs. New York, NBER.

Chaney, T., Sraer, D., \& Thesmar, D. (2012). The collateral channel: How real estate shocks affect corporate investment. American Economic Review, 102(6), 23812409. 
Claessens, S., Kose, M. A., \& Terrones, M. E. (2011, May). Financial cycles: what? how? when?. In International Seminar on Macroeconomics (Vol. 7, No. 1, pp. 303344). Chicago, IL: University of Chicago Press.

Claessens, S., \& Kose, M. M. A. (2013). Financial crises explanations, types, and implications (No. 13-28). International Monetary Fund.

Conefrey, T., \& Cronin, D. (2015). Spillover in euro area sovereign bond markets. The Economic and Social Review, 46(2, Summer), 197-231.

Dees, S. (2016). Credit, asset prices and business cycles at the global level. Economic Modelling, 54, 139-152.

Diebold, F. X., \& Yilmaz, K. (2009). Measuring financial asset return and volatility spillovers, with application to global equity markets. The Economic Journal, 119(534), 158-171.

Diebold, F. X., \& Yilmaz, K. (2012). Better to give than to receive: Predictive directional measurement of volatility spillovers. International Journal of Forecasting, 28(1), 57-66.

Goldsmith, R. W. (1969). Financial structure and development. New Haven: Yale University Press.

Gonzalez, R. B., Lima, J., \& Marinho, L. (2015). Business and financial cycles: an estimation of cycles' length focusing on Macroprudential Policy (Banco Central do Brasil Working Papers No. 385).

Harding, D., \& Pagan, A. (2002). Dissecting the cycle: a methodological investigation. Journal of monetary economics, 49(2), 365381.

Notice: The Journal of Indonesian Economy and Business and its Board of Editors are not responsible for any errors or flaws found in this article. The authors take full responsibility for their work.
Jordà, Ò., Schularick, M., \& Taylor, A. M. (2013). When credit bites back. Journal of Money, Credit and Banking, 45(s2), 3-28.

King, R. G., \& Levine, R. (1993). Finance, entrepreneurship and growth. Journal of Monetary economics, 32(3), 513-542.

Koop, G., Pesaran, M. H., \& Potter, S. M. (1996). Impulse response analysis in nonlinear multivariate models. Journal of econometrics, 74(1), 119-147.

López, M., Tenjo, F., \& Zárate, H. (2014). Credit cycles, credit risk and countercyclical loan provisions. Ensayos sobre Política Económica, 32(74), 9-17.

McKinnon, R. (1973). Money and capital in economic development. Washington, Brookings Institute.

Pesaran, H. H., \& Shin, Y. (1998). Generalized impulse response analysis in linear multivariate models. Economics letters, 58(1), 17-29.

Pouvelle, M. C. (2012). Bank credit, asset prices and financial stability: Evidence from French banks (No. 12-103). International Monetary Fund.

Rand, J., \& Tarp, F. (2002). Business cycles in developing countries: are they different? World development, 30(12), 2071-2088.

Robinson, J. (1952). The Generalization of the General Theory. In The Rate of Interest and Other Essays, London: MacMillan.

Shaw, E. S. (1973). Financial deepening in economic development. New York, Oxford University Press.

Schularick, M., \& Taylor, A. M. (2012). Credit booms gone bust: Monetary policy, leverage cycles, and financial crises, 1870-2008. American Economic Review, 102(2), 102961. 